\title{
The Role of a Medical Toxicologist for Assistance in the Treatment of Alcohol Withdrawal Syndrome
}

\author{
American College of Medical Toxicology
}

Published online: 12 May 2012

(C) American College of Medical Toxicology 2012

Keywords Alcohol withdrawal · Toxicologist · Mortality

\section{Background}

Alcohol (ethanol) withdrawal syndrome is a complex disorder which may present with a spectrum of clinical scenarios, including simple physical or mental discomfort, tremulousness, hallucinations of a tactile, auditory, or visual nature; discrete withdrawal seizures; status epilepticus; and delirium tremens $[1,13,14]$. The clinical presentation and therapy may differ significantly from that of medically intended or planned substance dependence treatment ("detox"). Clinical presentation and management may also vary according to the age of the patient, duration of use, concomitantly abused substances, prescribed pharmaceuticals, and acute or chronic underlying medical, surgical, or psychiatric illness. The clinician treating the patient with alcohol withdrawal syndrome should have a comprehensive understanding of the pathophysiology of alcohol withdrawal and be prepared to administer treatment carefully adapted to the clinical scenario(s) present and its (their) severity.

The differential diagnosis of alcohol withdrawal syndrome includes withdrawal from other sedative-hypnotic agents such as barbiturates, benzodiazepines, or gammahydroxybutyrate; drug-induced, agitated delirium, or acute intoxication with stimulants or pro-convulsant agents such as

Editor's note: This is a revision of a previously approved position statement.

American College of Medical Toxicology $(\varangle)$

10645 N. Tatum Blvd. Suite 200-111,

Phoenix, AZ 85028, USA

e-mail: jmt@acmt.net cocaine, amphetamines, phencyclidine, methylxanathines, anticholinergics, or ethylene glycol; delirium secondary to toxicological hyperthermias such as serotonin syndrome; and other deliriums and encephalopathies of toxic or nontoxic origin. The presence of complicating infections, such as meningitis, encephalitis, or pneumonia, which may also be entertained as part of the differential diagnosis, may make the diagnosis more difficult and significantly complicate management. Concomitant illness such as meningitis, encephalitis, pneumonia, sepsis, ketoacidoses, pancreatitis, and gastrointestinal hemorrhage may precipitate alcohol withdrawal. As the condition progresses, the ethanol-dependent individual decreases or ceases ethanol intake. The decision to diminish or abstain from ethanol intake may originate voluntarily or occur secondary to a lack of funds. Additionally, patients hospitalized for other reasons (medical illness, planned surgical interventions, or unanticipated traumatic injury) may either choose not to disclose or lack the capacity to disclose the full extent of their alcohol intake, and therefore may present in a delayed fashion [4].

\section{Morbidity and Mortality}

While the mortality of alcohol withdrawal syndrome has decreased with improvements in intensive care, a significant minority of these patients will die or experience significant morbidity either from the effects of withdrawal itself or from its complications, including cerebral hypoxia, infection, and rhabdomyolysis $[4,9,11,13]$. Failure to recognize and rapidly treat thiamine deficiency, intercurrent hypoglycemia, agitated delirium, and volume depletion may result in irreversible central nervous system damage, other organ systems injury, or persistent psychosis. 


\section{Benefits of Medical Toxicology Participation in Alcohol Withdrawal Syndrome Treatment}

Medical toxicologists have education, training, clinical experience, and practice in the pharmacotherapy, intensive care principles, diagnosis and management of alcohol withdrawal and other withdrawal syndromes. Given (1) the spectrum of alcohol withdrawal presentations; (2) a differential diagnosis which involves primarily drug intoxications or other forms of substance withdrawal; (3) the potential for rapid escalation of symptoms, significant morbidity, and mortality; (4) the potential requirement for "heroic" quantities of sedativehypnotics or central nervous system depressants in treatment; (5) the dangers of using medications which may mask or exacerbate withdrawal, which may be inappropriately applied to withdrawal manifestations, may interact with other pharmacotherapy, or may complicate the underlying illness; and (6) the need for intensive monitoring [2, 3, 5-8, 10,12,13]-early involvement of a medical toxicologist may be of significant benefit in the care of patients with alcohol withdrawal. The American College of Medical Toxicology strongly recommends participation by a medical toxicologist in the direct or indirect care of patients with suspected or confirmed alcohol withdrawal syndrome.

Disclaimer While individual practitioners may differ, this is the position of the American College of Medical Toxicology at the time written after a review of the issue and pertinent literature.

\section{References}

1. Adinoff B, Bone GHA, Linnoila M (1988) Acute ethanol poisoning and the ethanol withdrawal syndrome. Med Toxicol 3:172-196
2. Alldredge BK, Lowenstein DH, Simon RP (1989) Placebocontrolled trial of intravenous diphenylhydantoin for shortterm treatment of alcohol withdrawal seizures. Am J Med 87:645-648

3. Blum K, Eubanks JD, Wallace JE, Hamilton H (1976) Enhancement of alcohol withdrawal convulsions in mice by haloperidol. Clin Toxicol 9:427-434

4. de Wit M, Jones DG, Sessler CN, Zilberberg MD, Weaver MF (2010) Alcohol-use disorders in the critically ill patient. Chest 138:994-1003

5. Chance JF (1991) Emergency department treatment of alcohol withdrawal seizures with phenytoin. Ann Emerg Med 20:520 522

6. Eyer F, Schuster T, Felgenhauer N, Pfab R, Strubel T, Saugel B, Zilker T (2011) Risk assessment of moderate to severe alcohol withdrawal-predictors for seizures and delirium tremens in the course of withdrawal. Alcohol Alcohol 46:427-433

7. Gold JA, Rimal B, Nolan A, Nelson LS (2007) A strategy of escalating doses of benzodiazepines and phenobarbital administration reduces the need for mechanical ventilation in delirium tremens. Crit Care Med 35:724-730

8. Kaim SC, Klett CJ, Rothfeld B (1969) Treatment of the acute alcohol withdrawal state: a comparison of four drugs. Am J Psychiatry 125:1640-1646

9. Marik P, Mohedin B (1996) Alcohol-related admissions to an inner city hospital intensive care unit. Alcohol Alcoholism 31:393-396

10. Mayo-Smith MF (1997) Pharmacological management of alcohol withdrawal. A meta-analysis and evidence-based practice guideline. American Society of Addiction Medicine Working Group on Pharmacological Management of Alcohol Withdrawal. JAMA 278:144-151

11. Moss M, Bucher B, Moore FA, Moore EE, Parsons PE (1996) The role of chronic alcohol abuse in the development of acute respiratory distress syndrome in adults. JAMA 275:50-54

12. Rathlev NK, D’Onofrio G, Fish SS, Harrison PM, Bernstein E, Hossack RW, Pickens L (1994) The lack of efficacy of phenytoin in the prevention of recurrent alcohol-related seizures. Ann Emerg Med 23:513-518

13. Sarff M, Gold JA (2010) Alcohol withdrawal syndromes in the intensive care unit. Crit Care Med 38(9 Suppl):S494-S501

14. Stewart DG, Brown SA (1995) Withdrawal and dependency symptoms among adolescent alcohol and drug abusers. Addiction 90:627-635 